\title{
Research on the Historical Evolution and Hot Spots of Public Policy Making in China
}

\author{
Guangchen Wang* \\ College of Politics and Public Administration, Qingdao University, Qingdao City 266061, Shandong, China. E-mail: \\ guangchen0810@163.com
}

\begin{abstract}
Public policy formulation is the prerequisite and primary issue for public decision-making. This article uses the CiteSpace analysis software to make a detailed analysis of the research literature (1999-2019) on policy formulation in the CNKI database, and to sort out the historical evolution and hotspots of China's policy formulation research in the past two decades. The analysis found that: policy formulation, educational policy formulation, interest groups, and public participation are the focus of research in the field of policy formulation; the first ten years mainly focused on relevant theories and experiences of Western countries, as well as sustainable development and harmonious society. The next ten years mainly focused on research on public opinion, democracy, think tanks, and satisfaction.
\end{abstract}

Keywords: Public Policy Formulation; Historical Evolution; Hot Spots; CiteSpace

Public policy formulation is a regular activity of the public decision-making system in social and political life. Public policy-making institutions and their actual policy processes are relatively independent. The public policy as a product of the interaction between the policy subject and the environment and target groups will inevitably depend more on the behavior of the policy subject, that is, the policy maker. In order to make public policy formulation more reasonable, fairer and more effective, and to make policy content more able to reflect the public interests of society, the basic principles of rationalization, standardization, and democratization should be adhered to in the process of public policy formulation ${ }^{[1]}$.

\section{Principles of public policy for- mulation}

\subsection{Principle of rationality}

Rationality is one of the basic value orientations of modern public policy, and it is also a basic principle in the process of public policy making. Simon believes that in a broad sense, rationality refers to a way of behavior that is suitable for achieving specified goals within the limits of given conditions and constraints ${ }^{[2]}$. The action designed by "correctness" is that can seek the greatest success for the specified goal and its real situation ${ }^{[3]}$.

\subsection{Principle of standardization}

Standardization is an important principle of modern public policy formulation. The diversification of stakeholders in society and the complexity of the public policy formulation process internally require the standardization of public policy formulation and decision-making procedures. Standardization mainly includes three aspects: first, the standardization and legalization of institutional procedures; second, the openness of the policy formulation process; third, the diversification and scientificiza-

Copyright (C) 2020 Guangchen Wang

doi: 10.18282/ii.v2i2.361

This is an open-access article distributed under the terms of the Creative Commons Attribution Non-Commercial License

(http://creativecommons.org/licenses/by-nc/4.0/), which permits unrestricted non-commercial use, distribution, and reproduction in any medium,

provided the original work is properly cited. 
tion of policy formulation methods.

\subsection{Principle of democratization}

The democratization of decision-making is also an important value orientation in the formulation of modern public policies. It pursues social justice and emphasizes citizen participation. The formulation and implementation play a philosophical guiding role, and play an important role in regulation and coordination in the public policy field regulated by each ${ }^{[4]}$.

\section{Analysis of the knowledge graph of policy-making research in China}

The literature is selected from the China National Knowledge Infrastructure (CNKI), with the subject term of policy formulation during 1999-2019. The source category is CSSCI source journals, and a total of 329 papers are obtained. The document data is imported into the analysis tool CiteSpace to draw a knowledge map of policy-making research from 1999 to 2019.

\section{co-occurrence}

Keywords can reflect the essence of the research field and the content of the paper, and high-frequency keywords reflect the research hotspot and core of the field. It has been found that high-frequency keywords and hot keywords by recording the literature in the field of policy making include policy making, public policy, public policy formulation, education policy formulation, citizen participation, education policy, interest group, public participation (as seen in Table 1). For keywords in the field, the higher the intermediary centrality, the more important the node is in the network. From the table, it can be seen that the keywords policy making, public policy, public policy formulation, and education policy formulation have higher betweenness centrality, indicating that the policy making, public policy, and education policy formulation play a large role in literature research, which can be clearly seen from the frequency of occurrence.

\subsection{Keyword frequency and keyword}

Table 1. Hot keywords in the field of CSSCI policy making and keywords frequency

\begin{tabular}{|c|c|c|c|}
\hline Keywords & Frequency & Year & Betweenness centrality \\
\hline Policy making & 111 & 2001 & 0.52 \\
\hline Public policy & 74 & 1999 & 0.28 \\
\hline Public policy formulation & 37 & 2001 & 0.24 \\
\hline Education policy formulation & 24 & 1999 & 0.27 \\
\hline Citizen participation & 22 & 2003 & 0.11 \\
\hline Education policy & 22 & 2003 & 0.14 \\
\hline Interest group & 13 & 2005 & 0.09 \\
\hline Public participation & 12 & 2005 & 0.07 \\
\hline Policy process & 9 & 2009 & 0.05 \\
\hline Policy implementation & 8 & 2005 & 0.08 \\
\hline
\end{tabular}

\subsection{Analysis of keyword time zone}

In order to explore the changes in research hotspots from 1999 to 2019, this article uses the time zone view presentation function of CiteSpace keyword clustering. Select the time zone view in the CiteSpace cluster view, and an evolution view that focuses on the time dimension to represent knowledge can be obtained. The more connections there are, the closer the inheritance relationship between the two time zone nodes is. The evolution and development trend of policy-making research can be found out: before 2000, research focused on the formulation of public policies and education policies. In the first ten years, it mainly focused on theoretical and empirical research on the United Kingdom and the United States, as well as sustainable development and harmonious society. In the next ten years, the main focus was on research on public opinion, democracy, think tanks, and satisfaction. 


\subsection{Cluster analysis}

In the clustering results, the Modularity value is 0.826 , the larger of which, the better the network clustering. The value of Silhouette is $0.7129<1$, which is closer to 0.7 , indicating that the clustering effect has good reliability. It can be seen that the research on policy formulation centers on citizen participation, public interest, policy formulation, and public policy formulation. Research on education policy, policy implementation, and value orientation is distributed all around in a radial way. First, through visual analysis, it is found that there are many hotspots in policy formulation research, and the existing results are scattered in various fields. However, from the main direction, they mainly focus on the research of citizen participation, public interest and education policy formulation.

\section{Conclusion}

This article sorts out policy formulation principles, policy demonstrations and policy formulation models, and uses the visual analysis software CiteSpace to make a detailed analysis of the policy formulation research literature downloaded in the CSSCI database during the 20 years (1999-2019). The historical evolution and hotspots of China's policy formulation research are sorted out. It can be seen that the research on policy formulation in China is quite mature, but it is found through literature analysis that the research on policy formulation still needs to be in-depth. By recording high-frequency keywords and hot keywords in the policy-making field, it is discovered that policy making, public policy, public policy formulation, education policy formulation, citizen participation, education policy, interest group, and public participation are the focus of research in the policy-making field. Through the time zone chart, it can be found that the first ten years mainly focused on the study of theories and experiences of the United Kingdom and the United States, and the sustainable development of a harmonious society. In the next ten years, it mainly focused on research on public opinion, democracy, think tanks, and satisfaction. At the same time, the evolution analysis of research hotspots through keyword cluster analysis mainly summarized three clusters, and it has been found that the recent research hotspots are research on citizen participation, public interest and education policy formulation. CiteSpace is used to analyze the existing results in a certain field. The analysis results can be displayed in the form of charts. The results are intuitive and clear, which is conducive to the classification and summary of research results in this field, and is conducive to the search for future research directions. It is a useful tool for literature analysis.

\section{References}

1. Qian Z. On active special properties and operational principles of public policy-making system. Policy Science of Chinese Administration (Special Edition) 2001; 2: 63-64.

2. Simon H. The cornerstone of modern decision theory. Yang L, Xu L (translators). Beijing: Beijing Economic Press; 1989. p. 31-50.

3. Lindblom CE. Politics, economics and the welfare. New York: Publishing Company of Harper Brother; 1953. p. 38.

4. Jiang M, Cui G. The construction of the value principle system of public policy (in Chinese). Journal of Yunnan Administration Institute 2008; 10(6): 5254. 